\title{
Application of mathematical modelling for assessing the biological half-times of chromium and nickel in field studies
}

\author{
A TOSSAVAinen, M NURMinen, P MUtANen, AND S TOLA \\ From the Institute of Occupational Health, Helsinki, Finland
}

\begin{abstract}
The biological half-times of urinary chromium and nickel excretion and plasma nickel concentration were calculated for four welders and four electroplaters. A linear one-compartment kinetic model gave estimates of the half-times ranging from 15 to 41 hours for chromium in urine, from 17 to 39 hours for nickel in urine, and from 20 to 34 hours for nickel in plasma. The model allows a precise description to be made of a worker's state of exposure as affected by a varying concentration of the metals in the air.
\end{abstract}

Field studies on the kinetics of toxic substances have many practical problems and exposure chamber studies would usually be more appropriate, but they are seldom possible because of the expense of the chamber experiment, and the amount of worktime which the exposed subjects must give up. In connection with exposure to carcinogenic substances, ethical considerations prevent chamber experiments even though such an exposure would be common in industry. Some of the practical problems arising in field studies because of the failure of the workers to comply strictly with the study protocol may be overcome by using suitable theoretical models which can be estimated from and tested even with somewhat scarce and imperfect data. We present a mathematical approach for assessing the biological half-times of urinary chromium and nickel and plasma nickel in connection with occupational exposure to these substances.

\section{Materials and methods}

As this study is based on the data of two previous detailed studies, ${ }^{12}$ the study design and the methods of chemical analyses are described only briefly.

\section{CHROMIUM}

The urinary excretion of chromium was studied in a group of six male welders (mean age 27.5 years, range

Received 9 July 1979

Accepted 7 November 1979
21-34). Five of them welded high alloy $\mathrm{Cr}-\mathrm{Ni}$ steel and one mild steel only (compeer person). In the present study only the four most exposed subjects were included. Air and urine samples were collected during one work-week. The urine samples were collected at 0700,1100 , and 1600 every working day of the week. Air samples were collected with personal samplers each morning and afternoon from Monday to Friday inclusive so that the sampling time covered the whole work period.

Urinary chromium analyses were performed with electrothermal atomic absorption spectrophotometry (AAS), and the results were calculated per gram of excreted creatinine. The water-soluble fraction of the welding fume was analysed by both the AAS and s-diphenylcarbazide method which gave identical results within the analytical error of the two procedures indicating that the water-soluble chromium compounds were mostly hexavalent. The precision of the AAS analyses was about $5-10 \%$ expressed as a relative standard deviation of duplicate determinations.

NICKEL

Urinary and plasma nickel concentrations were studied in a group of four electroplaters exposed to water-soluble nickel sulphate and chloride. Three of the subjects were male (aged 29-30) and one female (subject C, aged 43). One store worker served as a compeer. Only the results for the exposed subjects are presented here. Air, urine, and plasma samples 
were collected during one work-week immediately after the workers' summer vacation. The urine and plasma samples were taken at 0700 and 1600 each day of the week. Air samples were collected with personal samplers from Monday to Friday inclusive so that the sampling time covered the whole work period. Analyses of both the air and biological samples were performed with AAS; urinary values were corrected to a specific weight of 1.018.

\section{THEORETICAL BACKGROUND}

The uptake, distribution, and excretion of pollutants during an inhalation exposure involve dynamic processes. Figure 1 shows the basic configuration for the general dynamic system. The actual phenomena

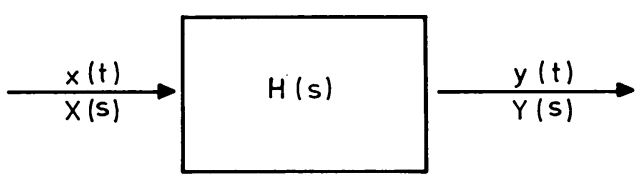

Fig 1 Schematic representation of one-compartment dynamic system. Input $=X(s), x(t) ;$ output $=Y(s), y(t)$; transfer function $=H(s)$.

in the body are complex, but for the purpose of this study we restrict attention to one input $x(t)$ and one output variable $y(t)$. The uptake rate $x(t)$ is assumed to be proportional to the nickel or chromium concentration in the inhaled air. The equation of this relationship is as follows:

$x(t)=k_{1} C(t)$

in which $\quad C(t)=$ metal concentration in air,

$\mathrm{t}=$ time, and

$\mathbf{k}_{1}=$ scaling constant.

For computation of the biological half-times the output $y(t)$ of the system is either the plasma concentration or the urinary excretion rate. The model to be developed represents a linear onecompartment system. This, the most simple model, depicts the body as a single homogeneous unit in which the inhaled material is mixed within one volume of distribution and excreted by a passive diffusion-type process. The first-order or linear kinetics means that the excretion rate is proportional to the amount of the metal in the body; expressed in the form of equations

$$
\begin{aligned}
y(t) & =k_{2} m, \\
\frac{d m}{d t} & =x(t)-y(t),
\end{aligned}
$$

in which $m=$ amount of the metal in the body, $\mathrm{d} / \mathrm{dt}=$ time differential,

$\mathbf{k}_{2}=$ scaling constant,

$x(t)=$ uptake rate, and

$y(t)=$ excretion rate.
It should be noted that the dimensions of $k_{1}$ and $k_{2}$ are different and dependant on the $x(t)$ or $y(t)$ definitions.

In the work-place the exposure or input $x(t)$ can be described as a series of consecutive doses. Mathematically, the time-varying concentration of the airborne pollutant is composed of a sum of step functions

$$
\left\{\begin{array}{ll}
u_{-1}(t)=0, & \text { for } t<0 \\
u_{-1}(t)=1, & \text { for } t \geqslant 0
\end{array} .\right.
$$

Linear systems provide the advantage of superposition. Thus if multiple inputs occur either together or apart, their effects can be calculated separately and the results combined to give the overall response. The use of Laplace transformations simplifies the discovery of the transfer function, because it converts difficult integration procedures in the time domain into multiplication in the s domain of the Laplace operator. If initial conditions are assumed to be zero and equation (2) is included, the Laplace-transformed version of the equation (3) is

$$
\mathrm{Ts} Y(\mathrm{~s})+\mathrm{Y}(\mathrm{s})=\mathrm{X}(\mathrm{s}) \text {, }
$$

in which $T=1 / k_{2}$, and

$$
\mathrm{Y}(\mathrm{s}), \mathrm{X}(\mathrm{s})=\text { Laplace transformations. }
$$

The transfer function $\mathrm{H}(\mathrm{s})$ of the first-order system obtains the form

$H(s)=\frac{Y(s)}{X(s)}=\frac{1}{T s+1}$,

which defines the output-input ratio in the s domain, and as such expresses the dynamic dependence of $y$ on $\mathrm{x}$. The equation, however, does not express timedomain functions except after the inverse Laplace transformation.

The transform pairs and the transient response of the unit step function in the first-order linear system are represented in fig $2 .{ }^{3}$ Now the uptake of the metal can be expressed as a sum of step functions

$$
x(t)=k_{1} \Sigma \Delta C_{i} u_{-1}\left(t-t_{i}\right), \quad\left(t \geqslant t_{i}\right)
$$

where $\Delta C_{i}$ is the measured, positive or negative change in the airborne metal concentration at time $t_{i}$. Then the response of the input $x(t)$ is

$$
\begin{array}{cc}
\mathrm{y}(\mathrm{t})=\mathrm{k}_{1} \Sigma \Delta \mathrm{C}_{\mathrm{i}}\left(1-\mathrm{e}^{-\left(\mathrm{t}-\mathrm{t}_{\mathrm{i}}\right) \mathrm{k}_{2}}\right), & (8, \text { model } \mathrm{I}) \\
\left(\mathrm{t} \geqslant \mathrm{t}_{\mathrm{i}}\right) .
\end{array}
$$

The term $\mathbf{k}_{\mathbf{2}}$ is the most important parameter of the first-order system and it relates to the biological halftime or elimination half-time simply as follows:

$\mathrm{T}_{1 / 2}=\frac{\ln 2}{\mathrm{k}_{2}}$

The factor $k_{1}$ is essentially a scaling constant. Calculation of the model entails the estimation of $T_{1 / 2}$ and $k_{1}$. By means of these parameters and by 

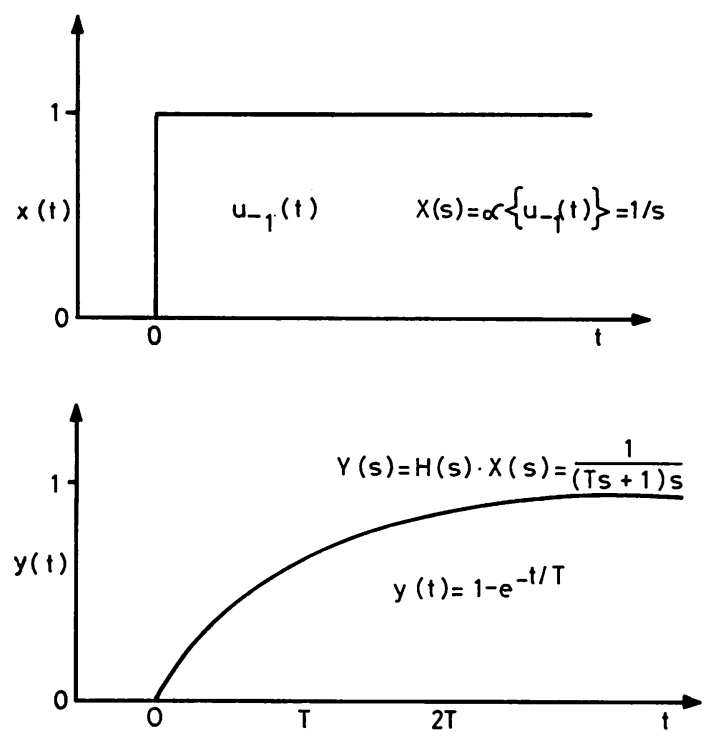

Fig 2 Transient response of unit step function in first-order linear system. $\alpha\{\cdot\}=$ Laplace transformation.

evaluating or measuring the volumetric breathing rate, absorption, and volumetric urinary excretion rate the metal accumulation in the body can be calculated, given the airborne pollutant concentration. To compensate for the dietary metal uptake and body burden a constant baseline concentration parameter $\mathbf{k}_{\mathbf{3}}$ can be added to the model:

$\mathrm{y}(\mathrm{t})=\mathrm{k}_{3}+\mathrm{k}_{1} \Sigma \Delta \mathrm{C}_{\mathrm{i}}\left(1-\mathrm{e}^{-\left(\mathrm{t}-\mathrm{t}_{\mathrm{i}}\right) \mathrm{k}_{2}}\right) \cdot(10$, model II $)$

\section{MODEL CONSTRUCTION AND FITTING}

A combined exponential model can be used to describe urinary and plasma nickel and chromium concentrations at certain time points. The measured quantities that are represented in the model are: (1) atmospheric concentration of nickel or chromium in the worker's breathing zone; (2) respective values of the concentrations in urine or plasma; and (3) recorded times of exposure and biological tests. The parameters to be estimated are: (1) scaling parameter $\left(\mathrm{k}_{1}\right)$, which accompanied with a further assumption of the individual's minute ventilation can be used to compute the accumulation or elimination rate; (2) half-time of the concentration $\left(T_{1 / 2}\right)$ in plasma or urine; and (3) base-line concentration $\left(\mathrm{k}_{3}\right)$, which principally describes the hypothetical non-exposed person's concentration; the absence or presence of this third parameter distinguishes the two models tried (models I and II).

For computation we have used the method of least squares: estimates of parameters obtained by this method minimise the error sum of squares between the observed values and the values predicted by the model. Numerical calculations were performed with a Wang 2200 minicomputer. The minimisation of the error sum of squares was done iteratively with the aid of two optimisation algorithms for non-linear model functions-the Davidon-Fletcher-Powell (DFP) method ${ }^{4}$ and Hooke-Jeeves (HJ) method. ${ }^{5}$ The former belongs to the family of gradient methods, the latter is a simple search method. In case of "well-behaved" models the choice is usually made in favour of the DFP method. For our model function, however, the computation of the derivatives needed in the DFP method was a slower process than operating with changes in the function value using the $\mathrm{HJ}$-algorithm. We thus applied the $\mathrm{HJ}$ method more frequently because it converged to the optimum point more rapidly in most runs than the DFP method.

Many different starting points were tried to ensure that the true minimum was found. These algorithms comprise one program modulus of the SURVO 76 statistical data processing system. ${ }^{6}$ They also provided estimates of the standard deviations (SD) of the model parameters. These approximate SDs were used to test the difference in the mean values of the parameters between two individuals in a standard $t$-test fashion.

The main measures used to assess the goodness-offit of the constructed models were: (1) the square of the multiple correlation coefficient $\left(\mathbf{R}^{2}\right.$-that is, the sum of squares due to regression divided by the total sum of squares); and (2) the coefficient of variation $\left(\mathrm{CV}_{\mathrm{e}}\right.$ - that is, the residual standard error expressed as a percentage of the mean concentration). As criterion values for an acceptable fit we used $\mathbf{R}^{2}>80 \%$ and $\mathrm{CV}_{\mathbf{e}}<20 \%$. In addition, we examined the pattern of residuals plotted against the measured concentrations and in time sequence.

\section{Results}

An example from our model fitting is displayed graphically in fig 3 , where the measured concentrations and the fitted values are presented for comparison. The complete empirical data and numerical results are given in appendices $I$ to $V$ and tables 1, 2, and 3. In general models I and II yielded nearly equal results. Nevertheless, we prefer model II to model I, because it includes the information on the level of the lowest concentration attained by the exposed workers during the study period. If the exposed person remained away from exposure this baseline parameter would eventually approach the nonexposed person's concentration. The nickel concentrations in urine (table 2) are well described by our models $\left(78 \% \leqslant \mathrm{R}^{2} \leqslant 99 \%, 4 \% \leqslant \mathrm{CV}_{\mathrm{e}} \leqslant 26 \%\right)$ 
Table 1 Results of fitting models to concentrations of chromium in urine versus chromium in air for four welders

\begin{tabular}{|c|c|c|c|c|c|c|c|c|}
\hline \multirow[t]{3}{*}{ Subject } & \multirow{2}{*}{\multicolumn{2}{|c|}{$\begin{array}{l}\text { Mean measured } \\
\text { concentration } \\
\text { during work-days }\end{array}$}} & \multirow[t]{3}{*}{ Model } & \multicolumn{3}{|c|}{ Estimated model parameters } & \multicolumn{2}{|c|}{ Measures of goodness-of-fit } \\
\hline & & & & \multirow{2}{*}{$\begin{array}{l}\text { Scaling constant } \\
10^{3} \times(\mu \mathrm{g} / \mathrm{g} \\
\text { creat }) /\left(\mathrm{mg} / \mathrm{m}^{3}\right)\end{array}$} & \multirow{2}{*}{$\begin{array}{l}\text { Half-time } \\
T_{1 / 2} \pm S D^{*} \\
\text { hours }\end{array}$} & \multirow{2}{*}{$\begin{array}{l}\text { Baseline } \\
\text { concentration } \\
\mu \mathrm{g} / \mathrm{g} \text { creatinine }\end{array}$} & \multirow{2}{*}{$\begin{array}{l}\text { Percentage } \\
\text { explained } \\
R^{2}(\%)\end{array}$} & \multirow{2}{*}{$\begin{array}{l}\text { Residual } \\
\text { error } \\
C V_{e}(\%)\end{array}$} \\
\hline & $\begin{array}{l}\text { In urine } \\
\mu \mathrm{g} / \mathrm{g} \text { creat }\end{array}$ & $\begin{array}{l}\text { In air } \\
m g / m^{3}\end{array}$ & & & & & & \\
\hline a & 85 & $0 \cdot 30$ & $\underset{\text { II }}{\text { I }}$ & $\begin{array}{l}1 \cdot 11 \\
1 \cdot 11\end{array}$ & $\begin{array}{l}27 \cdot 4 \\
27 \cdot 4\end{array} \pm 3 \cdot 9$ & $\overline{0.0}$ & $\begin{array}{l}81 \cdot 5 \\
81 \cdot 5\end{array}$ & $\begin{array}{l}12 \cdot 2 \\
12 \cdot 7\end{array}$ \\
\hline \multirow[t]{2}{*}{ b } & 75 & $0 \cdot 14$ & I & $1 \cdot 75$ & $34 \cdot 1 \pm 4 \cdot 4$ & - & $82 \cdot 1$ & $19 \cdot 2$ \\
\hline & & & II & 1.49 & $30 \cdot 4$ & $9 \cdot 6$ & 83.6 & $19 \cdot 2$ \\
\hline \multirow[t]{2}{*}{ c } & 48 & $0 \cdot 19$ & I & 0.83 & $14 \cdot 5 \pm 1 \cdot 6$ & $\overline{-}$ & $81 \cdot 4$ & $16 \cdot 2$ \\
\hline & & & II & 0.71 & $13 \cdot 3$ & $6 \cdot 5$ & $83 \cdot 0$ & $16 \cdot 2$ \\
\hline \multirow[t]{2}{*}{ d } & 18 & 0.02 & I & $2 \cdot 64$ & $41 \cdot 4 \pm 4 \cdot 7$ & - & $68 \cdot 1$ & $17 \cdot 4$ \\
\hline & & & II & $2 \cdot 38$ & $38 \cdot 3$ & $1 \cdot 3$ & $68 \cdot 9$ & $18 \cdot 0$ \\
\hline
\end{tabular}

*All subjects differ from each other $(t$-test, $p<0.001)$.

Table 2 Results of fitting models to concentrations of nickel in urine versus nickel in air for four subjects in an electroplating shop

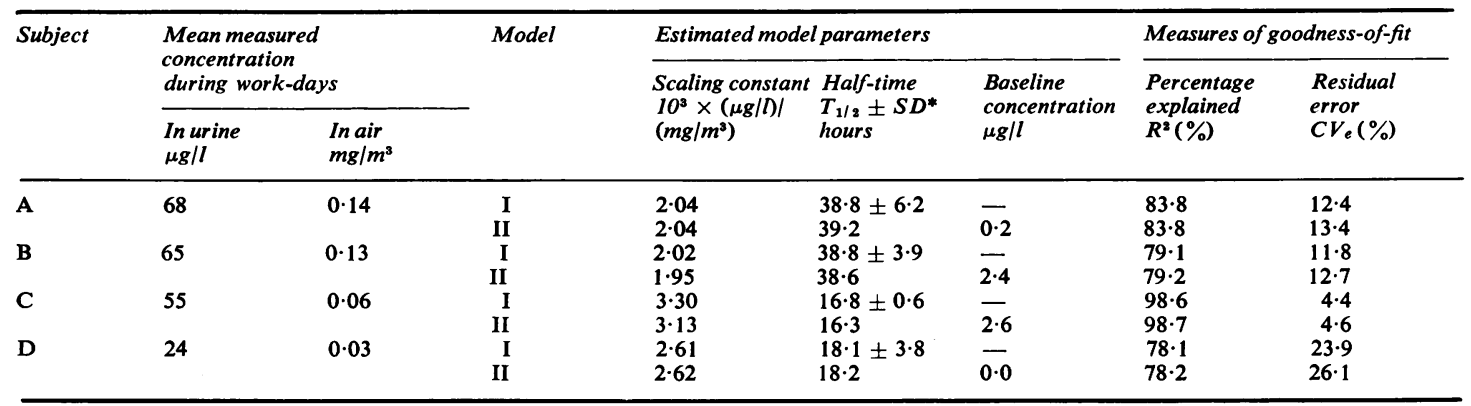

*Subjects A and B differ from C and D ( $t$-test, p $<0.001)$.

Table 3 Results of fitting models to concentrations of nickel in plasma versus nickel in air for four subjects in an electroplating shop

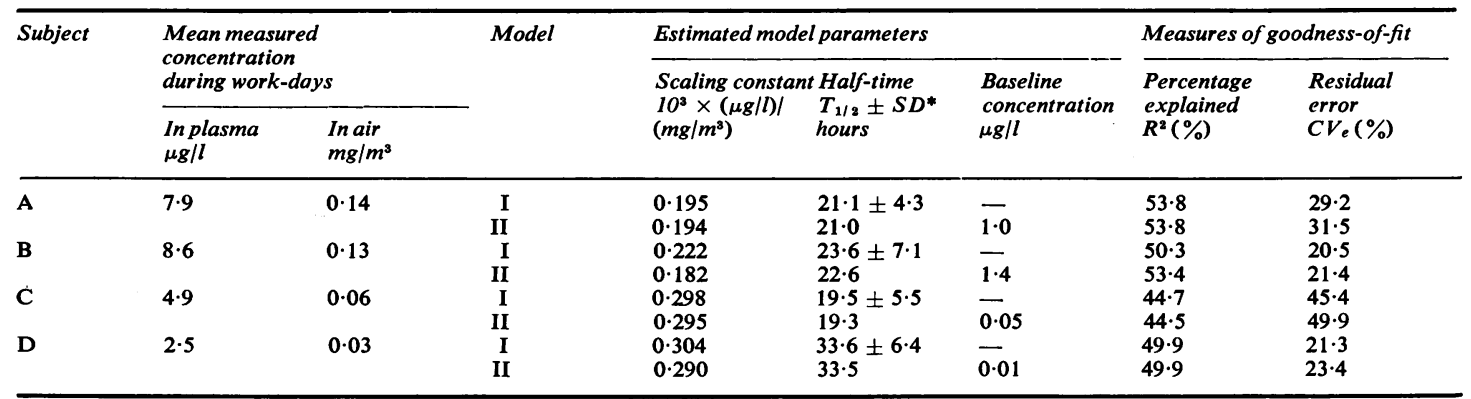

*Subjects A, B, and C differ from D ( $t$-test, p $<0.001)$.

For worker $\mathbf{D}$ there are indications of a poorer fit. The models provide likewise an adequate fit for the chromium concentrations in urine $\left(68 \% \leqslant \mathbf{R}^{2} \leqslant\right.$ $84 \%, 12 \% \leqslant \mathrm{CV}_{\mathrm{e}} \leqslant 19 \%$ ). Only for worker $\mathrm{d}$ does the percentage of explained variation, $\mathrm{R}^{2}$, fall below 80. The results for the nickel concentrations in plasma (table 3) do not indicate a good fit. For some workers the residual plotting against the measured concentrations disclosed non-randomness: when the observed concentration was high the model value was slightly low and vice versa.

The ranges of the half-times (for model I) extended 


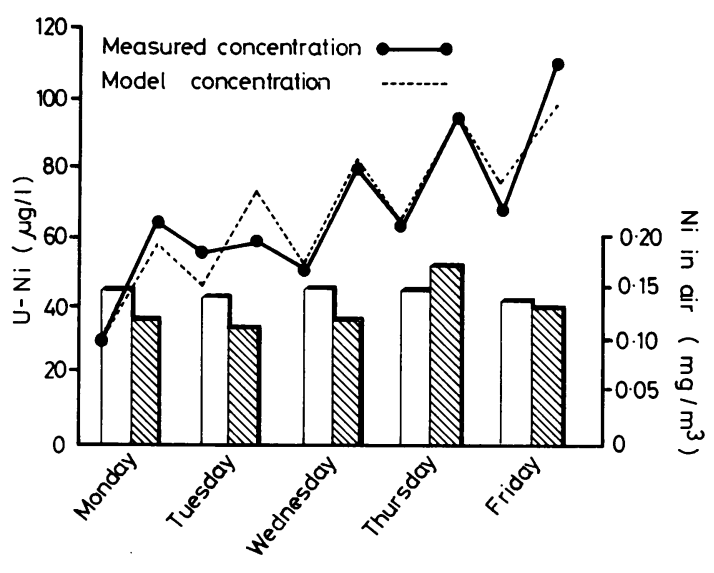

Fig 3 Urinary nickel concentrations for subject A during one working week. Bar diagrams represent nickel concentrations in air (am and pm).

from 15 to 41 hours for chromium in urine, 17 to 39 hours for nickel in urine, and from 20 to 34 hours for nickel in plasma. The differences between these extreme $T_{1 / 2}$ values were all statistically significant.

\section{Discussion}

Our point of departure in fitting a mathematical function to describe the observed data on nickel and chromium concentrations was the kinetic theory (model). An easier but, in our view, less fruitful approach would have been to fit a simple polynomial to describe the concentrations of these metals in a short period, say during a work-day. One advantage of the more complex function is that it allows a comprehensive description of a person's state of exposure as affected by varying uptake rates and urinary excretion. The consideration of all data points simultaneously has the added benefit of yielding more stable estimates of the model parameters. In other words we obtain more accurate values-for example, for the half-time of the nickel concentration in urine-than if we had fitted an exponential function to the exposure periods and off-exposure periods separately and by averaging obtained a value for the parameter of interest.

Yet another merit related to basing the form of the model function to an underlying theory is the possibility to build up the mathematical model iteratively. The kinetic theory initially implied the basic exponential form of the model function. Feedback from the applied model could modify or improve the theory. The implementation of new sources of variability, however, such as different perfusion rates and apparent volumes of distribution, would then necessitate the introduction of other parameters into the model. The use of Laplace transformation is a powerful and versatile tool for the derivation of the input-output relations, even if the simpler cases of transfer functions could directly be solved in the time domain. Our model was based on the assumption of one-compartment kinetics, which was known to be an oversimplification. A three-compartment model has been suggested for trivalent chromium, ${ }^{7} 8$ and Franchini et $a l^{9}$ have shown that the chromium clearance is dependent on the exposure level or body burden of the metal. The small number of observations compelled us to use the one-compartment model in practice but we also wanted to apply in the model construction the principle of parsimony. This means that as few parameters as possible should be included in the model function. We used two (model I) or three (model II) parameters to describe 10 observations for nickel and 15 for chromium (appendices I-V). We also tried a model in which the baseline concentration parameter was replaced by an estimated optimum one which liberated the fitted "sawblade-like" concentration function from passing through the first measured point. This added flexibility of the model function improved the goodness-of-fit considerably (on the average $10 \%$ in $\mathbf{R}^{2}$ ) for some workers. The reason for consideration of taking up this parameter was purely statistical: an exceptionally low Monday morning concentration (fig 3) forces the fitted function to start its track so much below the average observed concentration level that the principal deterministic behaviour of the function is not capable of adjusting to the observed course, and consequently the sum of squares criterion becomes large. We thought, however, that the accommodation of all three different free parameters in the model at the same time would require more observations to warrant their presence in the function.

Finally, it is perhaps pertinent to note that simple correlation and regression analyses are not mathematically appropriate methods to analyse these data because of the correlated nature of the observations. As compared to simple regression analysis, the present method provides the advantages of, firstly, being mathematically correct and, secondly, giving more information. As a practical advantage, the model allows the collection of biological samples at different points in time-no rigid sampling scheme is needed-only the time of sampling has to be known. The model may further be improved-for instance, to include simultaneous measurements of concentrations of air, plasma, and urine. 
Appendices

Appendix I Chromium concentrations in workplace air $\left(\mathrm{mg} / \mathrm{m}^{3}\right)$

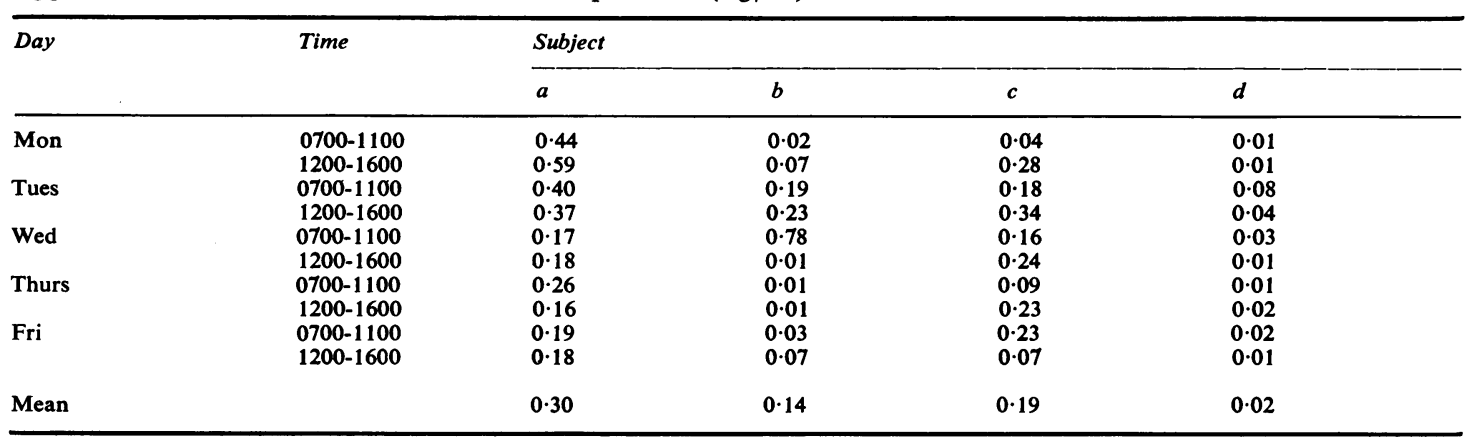

Appendix II Chromium concentrations in urine ( $\mu \mathrm{g} / \mathrm{g}$ creatinine). Observed and fitted values (model II)

\begin{tabular}{|c|c|c|c|c|c|c|c|c|c|}
\hline \multirow[t]{3}{*}{ Day } & \multirow[t]{3}{*}{ Time } & \multicolumn{8}{|c|}{ Subject } \\
\hline & & \multicolumn{2}{|l|}{$a$} & \multicolumn{2}{|l|}{$b$} & \multicolumn{2}{|l|}{$c$} & \multicolumn{2}{|l|}{$d$} \\
\hline & & Obs & Fitted & $O b s$ & Fitted & Obs & Fitted & Obs & Fitted \\
\hline Mon & $\begin{array}{l}0700 \\
1100 \\
1600\end{array}$ & $\begin{array}{r}21 \cdot 9 \\
62 \cdot 1 \\
117 \cdot 6\end{array}$ & $\begin{array}{r}21.9 \\
61.5 \\
113.2\end{array}$ & $\begin{array}{l}43.0 \\
41.0 \\
53.8\end{array}$ & $\begin{array}{l}43.0 \\
51.5 \\
55.5\end{array}$ & $\begin{array}{l}22 \cdot 7 \\
37 \cdot 5 \\
52 \cdot 1\end{array}$ & $\begin{array}{l}22 \cdot 7 \\
30 \cdot 0 \\
59 \cdot 3\end{array}$ & $\begin{array}{l}15 \cdot 2 \\
19 \cdot 4 \\
11 \cdot 7\end{array}$ & $\begin{array}{l}15 \cdot 2 \\
15 \cdot 9 \\
15 \cdot 1\end{array}$ \\
\hline Tues & $\begin{array}{l}0700 \\
1100 \\
1600\end{array}$ & $\begin{array}{r}60 \cdot 7 \\
110 \cdot 0 \\
134 \cdot 1\end{array}$ & $\begin{array}{r}77 \cdot 4 \\
107 \cdot 7 \\
131 \cdot 9\end{array}$ & $\begin{array}{r}40 \cdot 5 \\
50 \cdot 7 \\
109.9\end{array}$ & $\begin{array}{l}42 \cdot 2 \\
61 \cdot 1 \\
83 \cdot 5\end{array}$ & $\begin{array}{l}30.4 \\
39.7 \\
91 \cdot 3\end{array}$ & $\begin{array}{l}30 \cdot 7 \\
47 \cdot 4 \\
80 \cdot 1\end{array}$ & $\begin{array}{l}10 \cdot 9 \\
23 \cdot 5 \\
30 \cdot 1\end{array}$ & $\begin{array}{l}11 \cdot 9 \\
23 \cdot 1 \\
28 \cdot 2\end{array}$ \\
\hline Wed & $\begin{array}{l}0700 \\
1100 \\
1600\end{array}$ & $\begin{array}{r}71 \cdot 9 \\
88 \cdot 6 \\
103 \cdot 7\end{array}$ & $\begin{array}{r}90 \cdot 2 \\
97 \cdot 5 \\
104 \cdot 9\end{array}$ & $\begin{array}{r}71 \cdot 9 \\
129 \cdot 9 \\
152 \cdot 0\end{array}$ & $\begin{array}{r}62 \cdot 1 \\
146 \cdot 7 \\
132 \cdot 2\end{array}$ & $\begin{array}{l}36 \cdot 1 \\
54 \cdot 2 \\
80 \cdot 3\end{array}$ & $\begin{array}{l}40 \cdot 3 \\
52 \cdot 8 \\
71 \cdot 9\end{array}$ & $\begin{array}{l}19 \cdot 0 \\
23 \cdot 2 \\
23 \cdot 1\end{array}$ & $\begin{array}{l}21 \cdot 8 \\
24 \cdot 5 \\
22 \cdot 9\end{array}$ \\
\hline Thurs & $\begin{array}{l}0700 \\
1100 \\
1600\end{array}$ & $\begin{array}{r}62 \cdot 8 \\
108 \cdot 1 \\
98 \cdot 3\end{array}$ & $\begin{array}{l}71 \cdot 1 \\
88 \cdot 8 \\
94 \cdot 2\end{array}$ & $\begin{array}{l}86 \cdot 7 \\
71 \cdot 7 \\
78 \cdot 1\end{array}$ & $\begin{array}{l}96 \cdot 6 \\
89 \cdot 2 \\
81 \cdot 4\end{array}$ & $\begin{array}{l}39 \cdot 0 \\
42 \cdot 2 \\
50 \cdot 8\end{array}$ & $\begin{array}{l}36 \cdot 5 \\
41 \cdot 0 \\
61 \cdot 6\end{array}$ & $\begin{array}{l}15 \cdot 3 \\
17 \cdot 0 \\
14 \cdot 5\end{array}$ & $\begin{array}{l}17 \cdot 8 \\
16 \cdot 8 \\
18 \cdot 2\end{array}$ \\
\hline Fri & $\begin{array}{l}0700 \\
1100 \\
1600\end{array}$ & $\begin{array}{l}70 \cdot 6 \\
75 \cdot 7 \\
93.5\end{array}$ & $\begin{array}{l}64 \cdot 4 \\
76 \cdot 1 \\
85 \cdot 1\end{array}$ & $\begin{array}{l}68 \cdot 5 \\
69 \cdot 1 \\
60 \cdot 0\end{array}$ & $\begin{array}{l}60 \cdot 6 \\
59 \cdot 0 \\
62.2\end{array}$ & $\begin{array}{l}39 \cdot 1 \\
44 \cdot 7 \\
52 \cdot 5\end{array}$ & $\begin{array}{l}31 \cdot 8 \\
54 \cdot 1 \\
52 \cdot 3\end{array}$ & $\begin{array}{l}14 \cdot 0 \\
23 \cdot 3 \\
15 \cdot 7\end{array}$ & $\begin{array}{l}14 \cdot 2 \\
15 \cdot 5 \\
14.9\end{array}$ \\
\hline
\end{tabular}

Exposure and urinary chromium concentrations of the compeer person were less than $0.01 \mathrm{mg} / \mathrm{m}^{3}$ air and $20 \mu \mathrm{g} / \mathrm{g}$ creatinine.

Appendix III Nickel concentrations in workplace air (mgim $\left.{ }^{3}\right)$

\begin{tabular}{|c|c|c|c|c|c|}
\hline \multirow[t]{2}{*}{ Day } & \multirow[t]{2}{*}{ Time } & \multicolumn{4}{|c|}{ Subject } \\
\hline & & $A^{*}$ & $B$ & $C$ & $D$ \\
\hline \multirow{2}{*}{ Mon } & $0700-1100$ & $0 \cdot 15$ & $0 \cdot 13$ & 0.08 & 0.05 \\
\hline & $1200-1600$ & 0.12 & $0 \cdot 16$ & 0.04 & 0.03 \\
\hline \multirow[t]{2}{*}{ Tues } & $0700-1100$ & $0 \cdot 14$ & 0.13 & 0.05 & 0.02 \\
\hline & $1200-1600$ & $0 \cdot 11$ & $0 \cdot 11$ & 0.06 & 0.03 \\
\hline \multirow[t]{2}{*}{ Wed } & $0700-1100$ & $0 \cdot 15$ & $0 \cdot 12$ & 0.04 & 0.03 \\
\hline & $1200-1600$ & 0.12 & $0 \cdot 12$ & 0.06 & 0.04 \\
\hline \multirow[t]{2}{*}{ Thurs } & $0700-1100$ & 0.15 & 0.13 & 0.06 & 0.02 \\
\hline & $1200-1600$ & $0 \cdot 17$ & 0.15 & 0.07 & 0.04 \\
\hline \multirow[t]{2}{*}{ Fri } & $0700-1100$ & $0 \cdot 14$ & $0 \cdot 13$ & 0.06 & 0.03 \\
\hline & $1200-1600$ & 0.13 & $0 \cdot 14$ & 0.05 & 0.04 \\
\hline \multicolumn{2}{|l|}{ Mean } & $0 \cdot 14$ & $0 \cdot 13$ & 0.06 & 0.03 \\
\hline
\end{tabular}

*Cf fig 3. 
Appendix IV Nickel concentrations in urine ( $\mu g / l)$. Observed and fitted values (model II)

\begin{tabular}{|c|c|c|c|c|c|c|c|c|c|}
\hline \multirow[t]{3}{*}{ Day } & \multirow[t]{3}{*}{ Time } & \multicolumn{8}{|c|}{ Subject } \\
\hline & & \multicolumn{2}{|l|}{$A^{*}$} & \multicolumn{2}{|l|}{$\boldsymbol{B}$} & \multicolumn{2}{|l|}{$C$} & \multicolumn{2}{|l|}{$D$} \\
\hline & & Obs & Fitted & $O b s$ & Fitted & Obs & Fitted & Obs & Fitted \\
\hline \multirow[t]{2}{*}{ Mon } & 0700 & 29 & 29.0 & 31 & $31 \cdot 0$ & 25 & $25 \cdot 0$ & 12 & $12 \cdot 0$ \\
\hline & 1600 & 64 & 59.5 & 51 & $57 \cdot 7$ & 69 & 70.4 & 27 & $33 \cdot 2$ \\
\hline Tues & 0700 & 56 & $45 \cdot 7$ & 50 & 48.6 & 40 & 38.4 & 12 & $19 \cdot 0$ \\
\hline \multirow[t]{2}{*}{ Wed } & 0700 & 50 & 55.9 & 61 & 56.2 & 39 & $40 \cdot 0$ & 15 & 16.7 \\
\hline & 1600 & 81 & $82 \cdot 4$ & 79 & $77 \cdot 4$ & 79 & $74 \cdot 5$ & 41 & $36 \cdot 3$ \\
\hline \multirow[t]{2}{*}{ Thurs } & 0700 & 64 & 63.9 & 52 & $65 \cdot 3$ & 42 & $42 \cdot 3$ & 18 & 20.6 \\
\hline & 1600 & 95 & 94.9 & 81 & $86 \cdot 3$ & 82 & $84 \cdot 5$ & 42 & $34 \cdot 5$ \\
\hline \multirow[t]{2}{*}{ Fri } & 0700 & 68 & $74 \cdot 7$ & 73 & $67 \cdot 5$ & 47 & $47 \cdot 9$ & 22 & $20 \cdot 5$ \\
\hline & 1600 & 109 & $97 \cdot 7$ & 93 & 90.9 & - & - & - & - \\
\hline
\end{tabular}

*Cf fig 3.

Appendix V Nickel concentrations in plasma ( $\mu g / l)$. Observed and fitted values (model II)

\begin{tabular}{|c|c|c|c|c|c|c|c|c|c|}
\hline \multirow[t]{2}{*}{ Day } & \multirow[t]{2}{*}{ Time } & \multicolumn{8}{|c|}{ Subject } \\
\hline & & \multicolumn{2}{|l|}{$\boldsymbol{A}$} & \multicolumn{2}{|l|}{$\boldsymbol{B}$} & \multicolumn{2}{|l|}{$C$} & \multicolumn{2}{|l|}{$D$} \\
\hline Mon & 0700 & $3 \cdot 61$ & 3.61 & $4 \cdot 56$ & $4 \cdot 56$ & $2 \cdot 81$ & $2 \cdot 81$ & $1 \cdot 22$ & $1 \cdot 22$ \\
\hline \multirow{2}{*}{ Tues } & $\begin{array}{l}1600 \\
0700\end{array}$ & $10 \cdot 86$ & $8 \cdot 55$ & $9 \cdot 48$ & $10 \cdot 14$ & $6 \cdot 70$ & $6 \cdot 25$ & $2 \cdot 81$ & $2 \cdot 74$ \\
\hline & $\begin{array}{l}0700 \\
1600\end{array}$ & $\begin{array}{l}2 \cdot 70 \\
7 \cdot 49\end{array}$ & $\begin{array}{l}5 \cdot 44 \\
9 \cdot 22\end{array}$ & $\begin{array}{r}5.82 \\
10 \cdot 68\end{array}$ & $\begin{array}{r}7.08 \\
10.04\end{array}$ & $\begin{array}{l}2 \cdot 17 \\
5 \cdot 51\end{array}$ & $\begin{array}{l}3.63 \\
6.38\end{array}$ & $\begin{array}{l}1 \cdot 56 \\
3 \cdot 31\end{array}$ & $\begin{array}{l}2 \cdot 06 \\
2 \cdot 74\end{array}$ \\
\hline \multirow{2}{*}{ Wed } & 0700 & $7 \cdot 92$ & 5.89 & 8.80 & 7.09 & $3 \cdot 16$ & $3 \cdot 84$ & $2 \cdot 33$ & 2.05 \\
\hline & 1600 & $9 \cdot 71$ & 10.05 & $13 \cdot 34$ & 10.09 & $4 \cdot 25$ & 6.54 & $2 \cdot 43$ & $3 \cdot 26$ \\
\hline \multirow[t]{2}{*}{ Thurs } & 0700 & $7 \cdot 17$ & 6.42 & 6.95 & $7 \cdot 16$ & $1 \cdot 88$ & $3 \cdot 98$ & $2 \cdot 63$ & $2 \cdot 50$ \\
\hline & 1600 & $9 \cdot 12$ & $11 \cdot 52$ & 10.05 & 10.90 & 9.53 & $7 \cdot 26$ & $3 \cdot 85$ & $3 \cdot 33$ \\
\hline \multirow[t]{2}{*}{ Fri } & 0700 & $6 \cdot 35$ & $7 \cdot 36$ & $\begin{array}{l}6.59 \\
0.49\end{array}$ & $7 \cdot 58$ & $7 \cdot 81$ & $4 \cdot 45$ & $2 \cdot 28$ & $2 \cdot 52$ \\
\hline & 1600 & $\cdot 14$ & 11.01 & $9 \cdot 49$ & 11.09 & - & 一 & - & 一 \\
\hline
\end{tabular}

Exposure, urinary, and plasma concentrations of the compeer person were less than $0.01 \mathrm{mg} / \mathrm{m}^{3}$ air, $10 \mu \mathrm{g} / 1 \mathrm{urine}$, and $2 \mu \mathrm{g} / 1 \mathrm{plasma}$.

\section{References}

1 Tola S, Kilpiö J, Virtamo M, Haapa K. Urinary chromium as an indicator of the exposure of welders to chromium. Scand J Work Environ Health 1977;3:192-202.

2 Tola S, Kilpiö J, Virtamo M. Urinary and plasma concentrations of nickel as indicators of exposure to nickel in an electroplating shop. JOM 1979;21:184-9.

${ }^{3}$ Milsum JH. Biological Control Systems Analysis. New York: McGraw-Hill Book Company, 1966:121.

- Fletcher R, Powell MJP. A rapidly convergent descent method for minimization. Computer J 1964;7:163-8.

${ }^{5}$ Hooke R, Jeeves TA. Direct search solution of numerical and statistical problems. $J$ Assoc Computing Machinery $1961 ; 8: 212-29$.

- Mustonen S. SURVO 76 A Statistical Data Processing System. University of Helsinki: Department of Statistics, 1977. (Research Report No 6, May.)

7 Mutti A, Cavatorta A, Pedroni C, Borghi A, Giaroli C, Franchini I. Distribution and urinary excretion of chromium. Med Lav 1979;70:171-9.

${ }^{8}$ Metz W, Roginski EE, Reba RC. Biological activity and fate of trace quantities of intravenous chromium (III) in the rat. Am J Physiol 1965;209:489-94.

- Franchini I, Mutti A, Cavatorta A, et al. Nephrotoxicity of chromium. Contrib Nephrol 1978;10:98-110. 